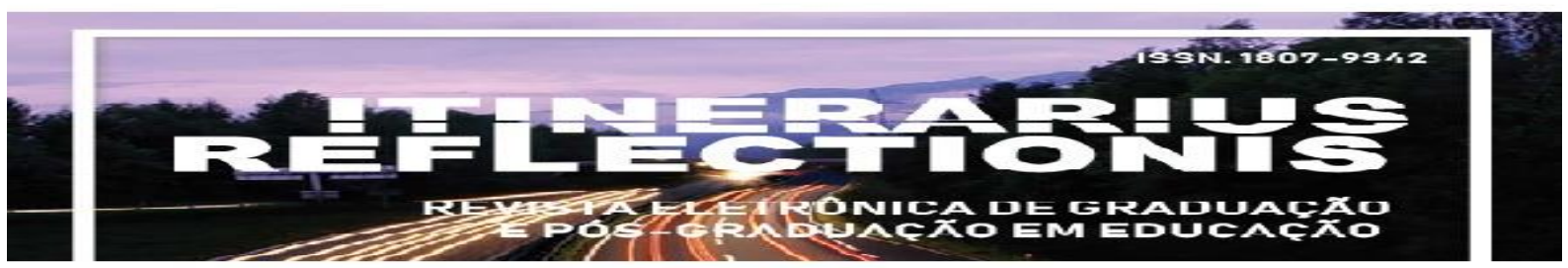

Volume, 15, número, 1, ano, 2019

\title{
MODELAGEM MATEMÁTICA COMO METODOLOGIA PARA O ENSINO APRENDIZAGEM DA MATEMÁTICA: REVISÃO DA LITERATURA.
}

\author{
Sória Pereira Lima Soares ${ }^{1}$
}

\begin{abstract}
Resumo. Este trabalho apresenta um levantamento, denominado "Estado da Arte", onde evidencia os pontos centrais das dissertações e teses sobre Modelagem Matemática entre o período de 1998 a 2017. Para realizar a pesquisa, servimo-nos do Banco de Teses da CAPEs e constatamos setenta e oito trabalhos a partir do termo "Modelagem Matemática" filtrados na área de conhecimento "Educação", sobre os quais foram realizadas análises mediante suas informações. A característica predominante da pesquisa foi qualitativa e os procedimentos de coleta e análise se aproximam de aspectos da análise de conteúdo. A condução desse estudo foi norteada pela seguinte questão: Quais são os objetivos das obras e o que dizem os resultados das dissertações e teses sobre o uso da Modelagem Matemática como metodologia para o ensino aprendizagem? Buscando responder a esse questionamento, ao decorrer do artigo, discutimos as diferentes abordagens existentes acerca do assunto. Verificou-se que os cenários de aplicação dessa metodologia contemplam a Educação Básica, Educação Tecnológica e Educação Superior. A modelagem matemática é uma alternativa para o processo de ensino-aprendizagem, com vários pontos benéficos e também desafios.
\end{abstract}

Palavras-chave: Modelagem Matemática. Revisão Bibliográfica. Ensino de Matemática.

\begin{abstract}
This work presents a research, called "State of Art", which shows the central points of dissertations and thesis on Mathematical Modeling between 1998 and 2017. To carry out the research, we used the Thesis Bank of CAPES and verified seventy-eight articles of the term "Mathematical Modeling" filtered in the area of knowledge "Education", in which the analyzes were carried out through their information. The predominant characteristic of the research was qualitative and the procedures of approach and analysis approach the aspects of content analysis. The conduction of this study was guided by the following question: what are the objectives of the works and what are the results of dissertations and theses about the use of Mathematical Modeling as teaching methodology? To answer this question, throughout the article, we discuss the different approaches that exist in the subject. It was verified that the application scenarios of this methodology include Basic Education, Technological Education and Higher Education. Mathematical modeling is an alternative to the teaching-learning process, with several beneficial points and also challenges.
\end{abstract}

Keywords: Mathematical Modeling. Literature revision. Mathematics Teaching.

\section{INTRODUÇÃO}

\footnotetext{
1 Mestranda do Programa de Pós Graduação em desenvolvimento Rural Sustentável e Gestão de Empreendimentos Agroalimentares. Instituto Federal de Educação, Ciência e Tecnologia do Pará.
} 


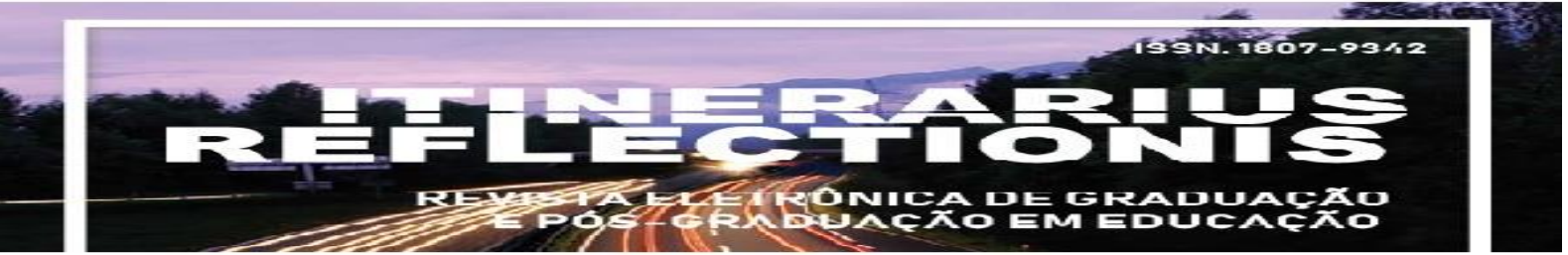

Volume, 15, número, 1, ano, 2019

Segundo Klüber (2010) a Modelagem Matemática na Educação Matemática ainda é uma prática recente no Brasil, aproximadamente trintas anos. Ainda assim, mesmo com a breve trajetória, ela é um assunto nos principais eventos da área da Educação Matemática, como nomeadamente: Encontro Nacional de Educação Matemática - ENEM, Seminário Internacional de Pesquisa em Educação Matemática - SIPEM. Conta ainda com eventos peculiares, como dentre outros: Conferência Nacional de Modelagem na Educação Matemática - CNMEM, Encontro Paranaense de Modelagem na Educação Matemática - EPMEM e Encontro Paraense de Modelagem Matemática - EPAMM, que realizou em 2016 sua sexta edição em Belém-Pa.

Diante disso, considerando o mérito da Modelagem Matemática para a Educação brasileira realizamos o seguinte estudo: "O que se tem investigado sobre Modelagem Matemática na Educação?" catalogado na descrição dos pontos centrais das dissertações e teses produzidas no país no período de 1998 a 2017. Este estudo deu alicerce para o que apresentamos neste artigo em que buscamos responder a seguinte questão: Quais são os objetivos das obras e o que dizem os resultados das dissertações e teses sobre o uso da Modelagem Matemática como metodologia para o ensino aprendizagem? O perfil da investigação fica mais perto daquilo que Ferreira (2002) intitula como "Estado da Arte". Segundo o autor, esses tipos de pesquisas tem em comum a instigação de analisar e debater uma obra acadêmica em distintas áreas do saber, na tentativa de responder que aspectos e proporções vêm sendo ressaído e apadrinhado em diferenciados tempos e localidades.

Podemos citar casos de trabalhos intitulados "Estado da Arte", tais como: Metodologias Ativas de Ensino-Aprendizagem: Revisão Integrativa (PAIVA et al, 2016); Modelagem Matemática em Educação no Brasil: entendendo o universo de teses e dissertações (SILVEIRA, 2007); Pesquisa em Ensino de Ciências na atualidade: um breve estado da arte de 1990 a 2010 (SANTANA; LIMA, 2011); As pesquisas denominadas do tipo "Estado da Arte" em Educação (ROMANOWSKI; ENS, 2006); O estado da arte da pesquisa em ensino de Biologia no Brasil: um panorama baseado na análise de dissertações e tese (TEIXEIRA; NETO, 2012). Todos os trabalhos citados foram realizados em diferenciados níveis de investigação, preconizando os estudos que reaquistam o rumo de outras pesquisas que foram realizadas em suas relativas áreas. 


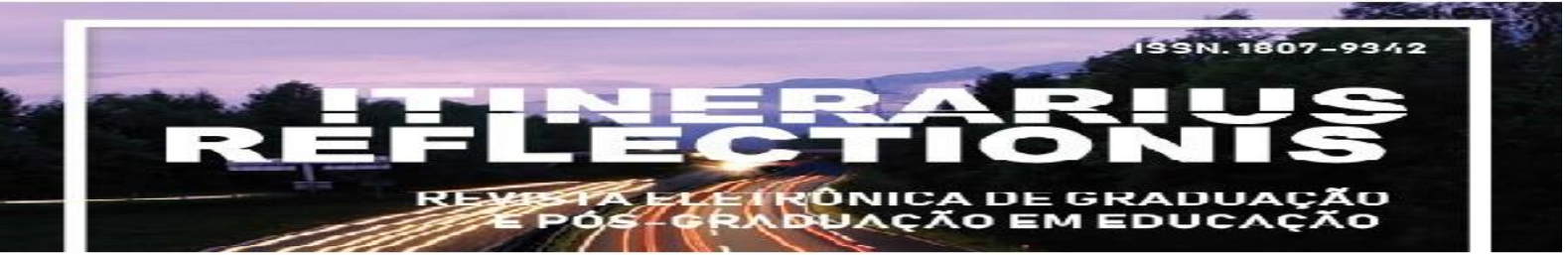

Volume, 15, número, 1, ano, 2019

De modo específico, no campo da pesquisa em Modelagem Matemática, que é o nosso ponto central, podemos mencionar o trabalho de Silva e Klüber (2012) que procurava sanar a seguinte questão: "Em que níveis de ensino estão focadas as pesquisas brasileiras sobre Modelagem Matemática na Educação Matemática e o que isso revela?" e o trabalho de Tambarussi e Klüber (2014) no qual procurou investigar os focos da pesquisa stricto sensu em Modelagem Matemática na Educação Matemática brasileira: considerações e reflexões.

Assim sendo, analisa-se, neste artigo, a utilização da modelagem matemática como metodologia para o ensino aprendizagem da matemática, a partir de uma revisão da literatura, com objetivos específicos: 1) Reconhecer os cenários de utilização da modelagem matemática; 2) Definir os benefícios e desafios do uso da metodologia no processo de ensino-aprendizagem.

Todas as obras mencionadas em momento anterior exteriorizam, dentro de cada assunto central, a viabilidade de prosseguir nas investigações, isto é, observar os assuntos ainda não interpelados, ou até mesmo continuar os estudos já iniciados.

Destinando-se a alvitrar uma comunicação com a Modelagem Matemática, que é o nosso campo de investigação, relataremos na seção seguinte alguns pontos de vistas a respeito da Modelagem Matemática. Disporemos este artigo perante a estrutura a seguir: Modelagem Matemática: Conceitos; Metodologia: Coleta e Verificação; Resultados e Discussão.

\section{MODELAGEM MATEMÁTICA: CONCEITOS}

A Modelagem Matemática traduz-se em um processo no qual a experiência cotidiana do aluno é aproveitada no ambiente acadêmico. Também podemos afirmar que a Modelagem Matemática trata-se de uma metodologia, cuja a proposta é oferecer aplicabilidade da matemática em situações da vida real. Assim, o objetivo dessa metodologia é dar um sentido ao conteúdo estudado, gerando uma facilidade maior na sua aprendizagem.

A Modelagem Matemática faz parte de um grupo de tendências que tem se destacado atualmente no mundo da Educação matemática, as quais visam proporcionar aos alunos aulas mais proveitosas e motivadoras. Nessa conjuntura, a Modelagem é encarada como umas das metodologias que concentra-se na melhoria da atuação dos professores e dos alunos no processo ensino-aprendizagem. 


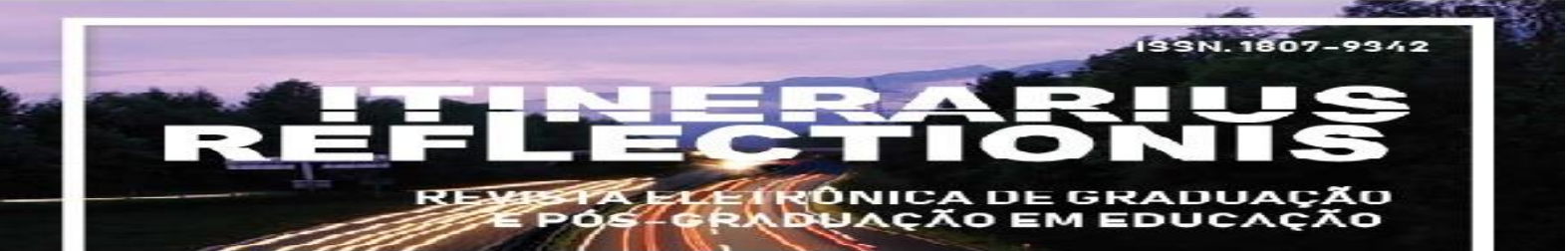

Volume, 15, número, 1, ano, 2019

Uma parcela significante dos pesquisadores tem o hábito de combinar a Modelagem no ensino da matemática com as experiências extra sala de aula. Para Bassanezi, "A Modelagem Matemática consiste na arte de transformar problemas da realidade em problemas matemáticos e resolvê-los interpretando suas soluções na linguagem do mundo real" (2002, p. 16). Ferreira afirma que "a Modelagem Matemática, entendida como uma estratégia de ensinoaprendizagem, na qual os alunos transformam problemas da realidade em problemas matemáticos...” (2003, p. 51). Segundo Sadovsky (2007) o importante do processo da modelação é o reconhecimento de uma situação problema, a seleção de uma teoria para tratá-la e a produção de novo conhecimento, conforme a demonstrado na figura 1.

Figura 1: Esquema de leitura analítica

\begin{tabular}{|c|}
\hline $\begin{array}{c}\text { Identificar uma situação } \\
\text { problema do cotidiano }\end{array}$ \\
\hline $\begin{array}{c}\text { Identificar o conjunto de } \\
\text { variáveis relativas ao } \\
\text { problema }\end{array}$ \\
\hline $\begin{array}{c}\text { Fazer a correlação das } \\
\text { variáveis com a situação } \\
\text { problema }\end{array}$ \\
\hline $\begin{array}{c}\text { Transformar as relações } \\
\text { em um sistema } \\
\text { matemático }\end{array}$ \\
\hline $\begin{array}{c}\text { Produzir novos } \\
\text { conhecimentos sobre a } \\
\text { temática }\end{array}$ \\
\hline
\end{tabular}

Fonte: Adaptado de Sadovsky (2007) 


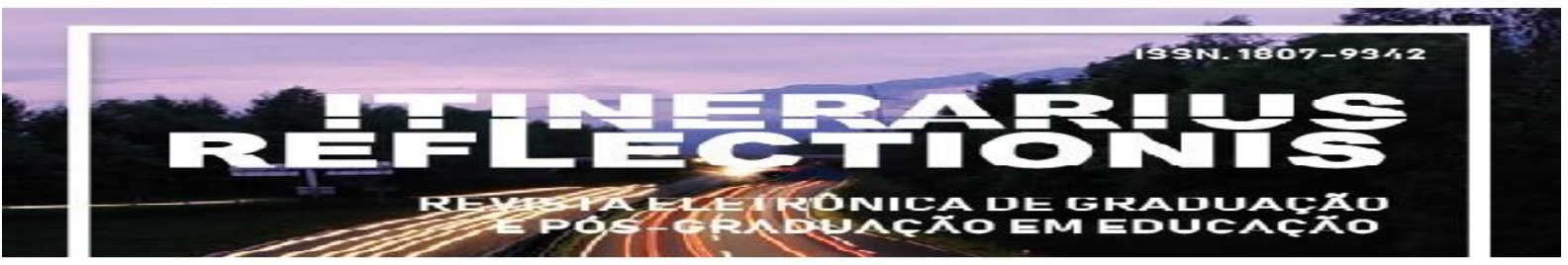

Volume, 15, número, 1, ano, 2019

E para reforçar temos Cristofoletti (1999, p. 47) que define a Modelagem Matemática como "Qualquer representação simplificada da realidade ou de um aspecto do mundo real que surja como de interesse ao pesquisador, que possibilite reconstruir a realidade, prever um comportamento, uma transformação ou uma evolução".

Esses autores fazem a relação da Modelagem Matemática com as "situações problemas", distintamente de Nina (2005), que usa a Modelagem Matemática para avizinhar "os mundos real e matemático". Stahl (2003) discursa sobre "modelação de fenômenos ambientais", ao mesmo tempo que Anastácio (1990) faz relação entre a prática da Modelagem Matemática ao que nomeia de "mundo-vida do aluno". Para finalizar, Macintyre (2005), ao promover atividades de Modelação Matemática com seus educandos do curso de Administração, cita a Modelação Matemática norteada para o "campo profissional do aluno".

Ao mencionar os autores acima, lembramos de algumas das atividades de Modelagem na Educação Matemática desenvolvidas pelos pesquisadores, e como consequência lembramos do D'Ambrosio, o qual levanta a seguinte questão: "Por que Educação e Educação Matemática e o próprio fazer matemático se não percebemos como nossa prática pode ajudar a construir uma humanidade ancorada em respeito, solidariedade e cooperação?” (1998, p. 13).

Bassanezi declara que um dos objetivos da Modelagem na Educação Matemática é estabelecer com que os alunos se organizem "para a vida real como cidadãos atuantes na sociedade, competentes para ver e formar juízos próprios, reconhecer e entender exemplos representativos de aplicações de conceitos matemáticos" (2002, p. 36). Com este conceito, o autor consegue revelar como a Modelagem na Educação Matemática tem contribuído com a formação político-social do aluno. Afinal de contas, o autor Fiorentini (1996) garante que a Modelagem no Ensino da Matemática no Brasil tem uma implicação mais social e antropológica, segundo os estudos de D’Ambrosio, que procura estabelecer a Modelagem Matemática no âmbito da Etnomatemática.

A utilização da modelagem como estratégia de ensino promove a pesquisa de outros campos do conhecimento através da matemática: “[...] modelagem é um ambiente de aprendizagem no qual os alunos são convidados a indagar e/ou investigar, por meio da matemática, situações oriundas de outras áreas do conhecimento" (BARBOSA, 2002, p. 6). 


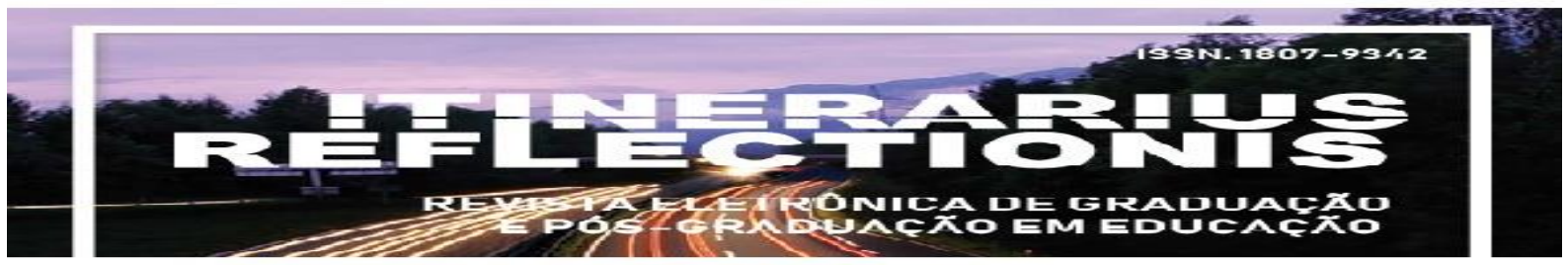

Volume, 15, número, 1, ano, 2019

3 METODOLOGIA: COLETA E VERIFICAÇÃO

Trata-se de uma revisão de literatura com coleta de dados processada por meio de fontes secundárias, através de pesquisa bibliográfica e fundamentada no acúmulo de conhecimentos vivenciados pelos autores (SOUZA et al, 2010).

Na pesquisa os estudos podem exteriorizar a possibilidade de observar os assuntos ainda não interpelados, ou até mesmo continuar os estudos já iniciados.

Conforme já declaramos, neste artigo procuramos sanar a questão: Quais são os objetivos das obras e o que dizem os resultados das dissertações e teses sobre o uso da Modelagem Matemática como metodologia para o ensino aprendizagem da matemática?

Para respondermos a questão, servimo-nos do Banco de Teses da Capes, disponível em plataforma eletrônica, no qual investigamos com os seguintes critérios de inclusão: 1) Presença do termo de busca "modelagem matemática"; 2) Tipo: Dissertações e Teses; 3) Recorte temporal do período de 1998 a 2017; 4) Área de conhecimento: Educação.

Posteriormente, realizamos uma pesquisa denominada "Estado da Arte", que segundo Ferreira (2002, p. 258) "é definida como caráter bibliográfico”, e busca

[...] responder que aspectos e dimensões vêm sendo destacados e privilegiados em diferentes épocas e lugares, de que formas e em que condições têm sido produzidas certas dissertações de mestrado, teses de doutorado, publicações em periódicos e comunicações em anais de congressos e seminários.

Foram selecionados 78 trabalhos, onde levantamos as principais informações: título; objetivo, cenários de utilização da modelagem matemática, benefícios e desafios do uso dessa metodologia e resumo.

Após o mapeamento, detectamos que cinquenta e sete correspondem a dissertações de mestrado e vinte e uma correspondem a teses de doutorado. Em seguida, iniciamos a fase de leitura e análise das obras selecionadas. A maneira pela qual executamos essa fase se aproxima do procedimento disposto por (SEVERINO, 2007, p. 64), na figura 2. 


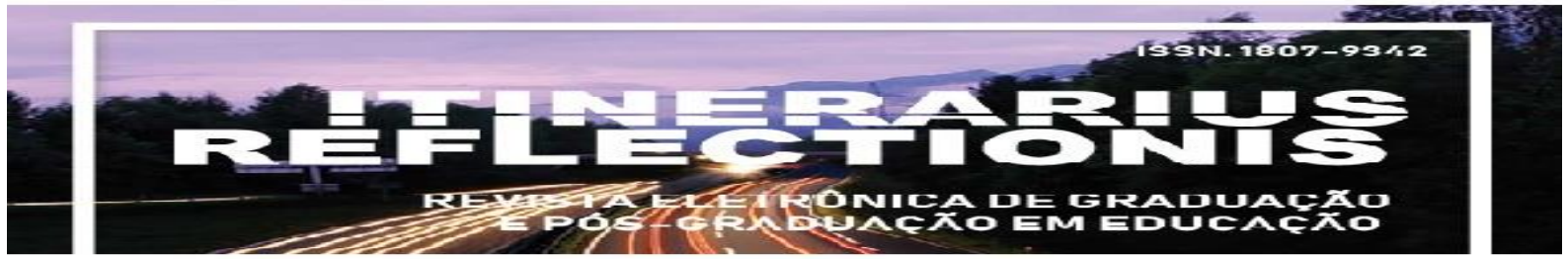

Volume, 15, número, 1, ano, 2019

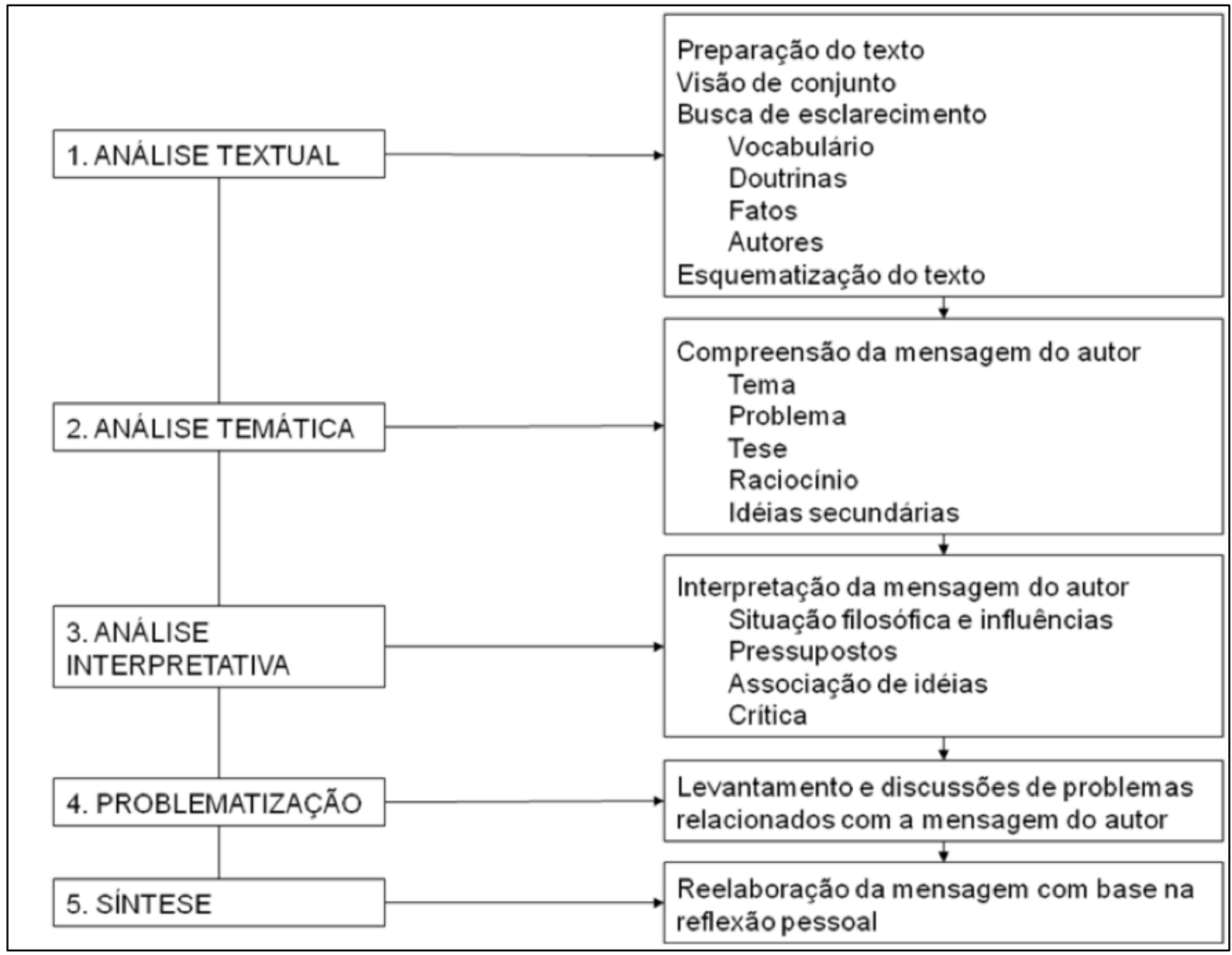

Fonte: Severino (2007, p. 64)

Levando em consideração esse conceito realizamos a leitura dos resumos dos trabalhos com a intenção de conhecer os assuntos mencionados para reconhecer os pontos centrais de cada investigação levantada.

\section{RESULTADOS E DISCUSSÃO}

A interpretação visa esclarecer a questão assumida como norteadora da investigação: Quais são os objetivos das obras e o que dizem os resultados das dissertações e teses sobre o uso da Modelagem Matemática como metodologia para o ensino aprendizagem? Neste item esclareceremos quais abordagens estão sendo creditadas à Modelagem no Ensino da Matemática pelos pesquisadores. Apenas para elucidar, citamos duas delas: estratégia de ensino e aprendizagem e proposta metodológica. 


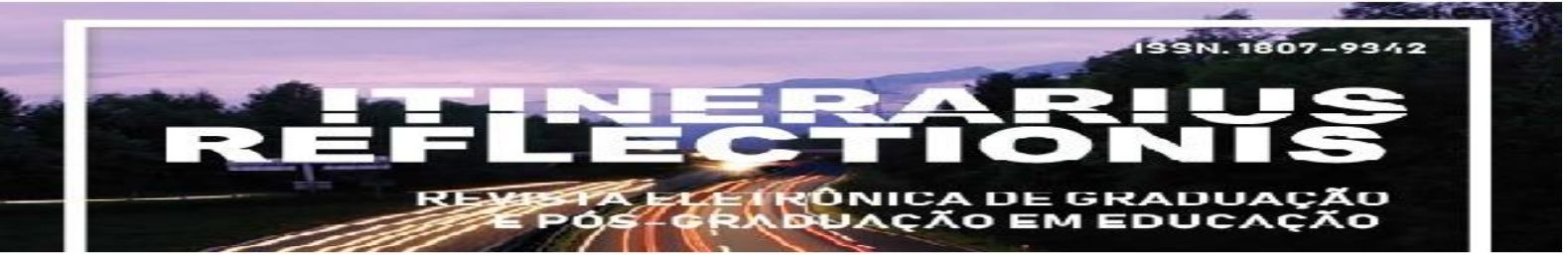

Volume, 15, número, 1, ano, 2019

Ao seguir uma determinada perspectiva da Modelagem Matemática estamos explanando a nossa forma de entender essa metodologia, que por sua vez, irá repercutir na nossa prática e também no decorrer da pesquisa em Modelagem Matemática.

Prosseguindo, buscamos apresentar as distintas maneiras de se conceber a Modelagem Matemática utilizadas nas obras analisadas.

Na utilização da Modelagem Matemática como proposta metodológica, atribui-se a concepção de Burak (1992). Segundo o autor, a Modelagem Matemática é "um conjunto de procedimentos cujo objetivo é construir um paralelo para tentar explicar, matematicamente, os fenômenos presentes no cotidiano do ser humano, ajudando-o a fazer predições e a tomar decisões" (BURAK, 1992, p. 62).

Já no entendimento da Modelagem Matemática enquanto estratégia de ensino e aprendizagem é "uma explicação, uma ressalva para a utilização da Modelagem Matemática no âmbito da educação, inclusive recebendo o nome de modelação" (KLÜBER, 2012, p. 213).

Contrariando ainda, temos Bassanezi (2002) que defende a Modelagem Matemática como uma estratégia de intervenção sobre a realidade, através do processo de criação de modelos.

Em breviário, a frequência e o discurso de distintas concepções de Modelagem Matemática, nas obras de mestrado e doutorado, mostram o enaltecimento de cada um dos conceitos.

Outrossim, além das obras terem sido desenvolvidas em distintas perspectivas, também foram realizadas em diferentes níveis e modalidades de ensino, como a: Educação Básica, Educação de Jovens e Adultos (EJA), Ensino Técnico e Ensino Superior.

No processo de leitura analítica das obras, identificamos que os trabalhos com foco na utilização da Modelagem matemática em sala de aula, estão sendo realizados com frequência nas pesquisas em Modelagem Matemática.

Em nossa pesquisa, podemos apontar ainda obras que: tratam do desenvolvimento do pensamento reflexivo, da participação dos alunos na construção do conhecimento que ocorrem no ambiente de Modelagem Matemática e do crescimento político dos alunos. E trabalhos que abordaram diferentes conteúdos matemáticos através da Modelagem Matemática, esta utilizada 


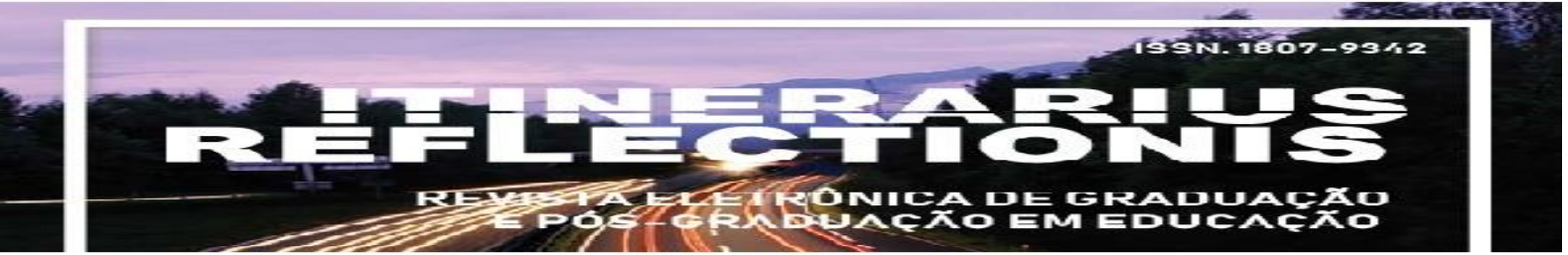

Volume, 15, número, 1, ano, 2019

como estratégia para o ensino e aprendizagem. A diversidade dos conteúdos pode ser justificada pelo fato das pesquisas serem aplicadas em todos os níveis de ensino.

Em outra perspectiva, temos as pesquisas que buscam relatar a Modelagem matemática em conjunto com outras teorias, como por exemplos: a teoria da socialização do conhecimento de Vygotsky; a aprendizagem significativa crítica; a transposição didática; os mapas conceituais; a produção de sentidos e a teoria das representações semióticas.

E finalizando, apresentam-se as obras que investigaram as impressões, experiências, tensões, concepções de professores e futuros professores de Matemática comprometidos com a Modelagem Matemática.

\section{CONSIDERAÇÕES}

A pesquisa do "Estado da Arte" sobre a Modelagem Matemática na Educação, especificamente no ensino da Matemática, nos dá base para o discernimento daquilo que tem sido investigado sobre a temática. As reflexões realizadas dão consentimento para responder a pergunta norteadora deste artigo: Quais são os objetivos das obras e o que dizem os resultados das dissertações e teses sobre o uso da Modelagem Matemática como metodologia para o ensino aprendizagem?

Além de apontar os pontos centrais mais frequentes nas investigações de Modelagem matemática, nossa pesquisa mostrou alguns dos vários rumos que são trilhados na utilização da Modelagem Matemática.

O pesquisa mostra que a Modelagem Matemática serve como estratégia para o ensino e aprendizagem da matemática estimulando conhecimentos, incentivando reflexões e desafiando para resolução de problemas, ou seja, é possível trabalhar todos os níveis do domínio cognitivo: conhecimento, compreensão, aplicação, análise, síntese e julgamento.

Torcemos para que os docentes sejam receptivos com essa metodologia de ensino, e utilizem em suas aulas, e que todos tenham acesso e possam desfrutar dos benefícios da Modelagem Matemática.

\section{REFERENCIAS}




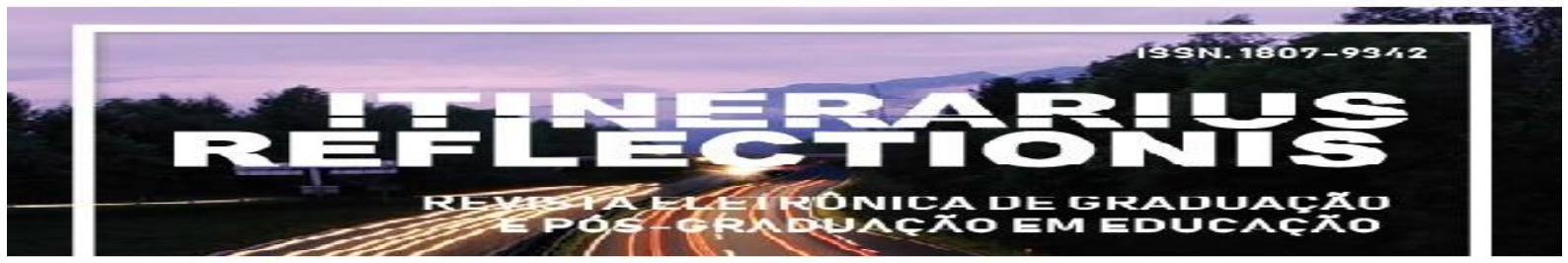

Volume, 15, número, 1, ano, 2019

ANASTÁCIO, Maria Queiroga Amoroso. Considerações sobre a modelagem matemática e a educação matemática. 1990. 100 p. Dissertação (Mestrado em Educação Matemática) Instituto de Geociências e Ciências Exatas, Universidade Estadual Paulista, Rio Claro, 1990.

BARBOSA, J. C. Modelagem matemática e os futuros professores. In: REUNIÃO ANUAL DA ANPED, 25, 2002, Caxambu. Anais. Caxambu: ANPED, 2002.

BASSANEZI, Rodney Carlos. Ensino-aprendizagem com modelagem matemática: uma nova estratégia. São Paulo: Contexto, 2002.

BORSSOI, Adriana Helena. A aprendizagem significativa em atividades de modelagem matemática como estratégia de ensino. 2004. 140 p. Dissertação (Mestrado em Ensino de Ciências e Educação Matemática) - Departamento de Matemática, Universidade Estadual de Londrina, Londrina, 2004.

BURAK, Dionísio. Modelagem matemática: ações e interações no processo de ensino aprendizagem. 1992. 459 p. Tese (Doutorado em Educação) - Faculdade de Educação, Universidade Estadual de Campinas, Campinas, 1992.

CRISTOFOLETTI, A. A modelagem de sistemas ambientais. São Paulo: Edgard Blücher, 1999.

D’AMBRÓSIO, Ubiratan. Educação matemática: da teoria à prática. Campinas: Papirus, 1998.

FERREIRA, Denise Helena Lombardo. O tratamento de questões ambientais através da modelagem matemática: um trabalho com alunos do ensino fundamental e médio. 2003. 278 p. Tese (Doutorado em Educação Matemática) - Instituto de Geociências e Ciências Exatas, Universidade Estadual Paulista, Rio Claro, 2003.

FERREIRA, N. S. de A. As pesquisas denominadas "estado da arte". Educação \& Sociedade, Campinas, v. 79, p. 257-272, 2002.

FIORENTINI, D. Estudo de algumas tentativas pioneiras de pesquisa sobre o uso da modelagem matemática no ensino. In: ICME, 8, 1996, Sevilha. Anais. Sevilha: ICME, 1996.

KLÜBER, T. E. (2010). Modelagem Matemática: revisitando aspectos que justificam a sua utilização no ensino. In Modelagem Matemática uma perspectiva para a Educação Básica. Ponta Grossa: Editora UEPG, 97-114.

NINA, Clarissa Trojack Della. Modelagem matemática e novas tecnologias: uma alternativa para a mudança de concepções em Matemática. 2005. 133 p. Dissertação 


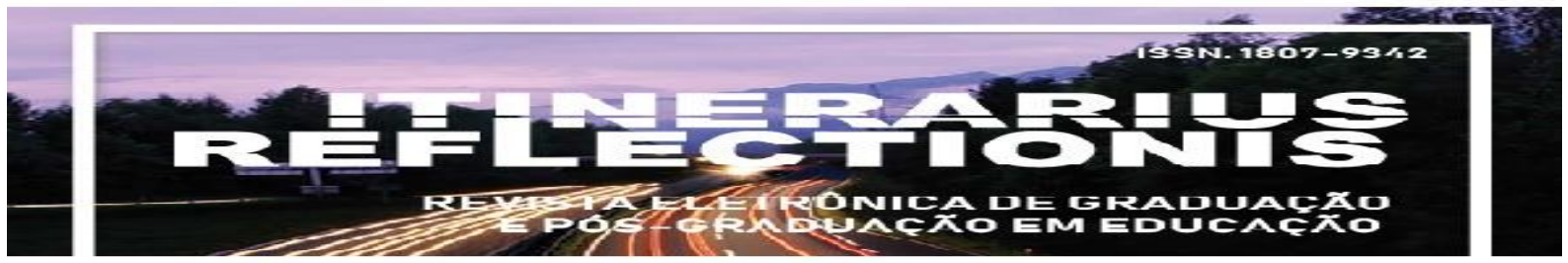

Volume, 15, número, 1, ano, 2019

(Mestrado em Educação em Ciências e Matemática) Pontifícia Universidade Católica do Rio Grande do Sul, Porto Alegre, 2005.

PAIVA, M. R. F.; PARENTE, J. R. F.; BRANDÃO, I. R. \& QUEIROZ, A. H. B. "Metodologias Ativas de Ensino Aprendizagem: Revisão Integrativa". Sanare, Sobral, vol. 15, n. 2, pp. 145-153, 2016.

ROMANOWSKI, J.P; ENS, R. T. (2006). As pesquisas denominadas do tipo "Estado da Arte" em Educação. In Revista Diálogo Educacional. Curitiba (PUC/PR). v. 6. n. 19, 37-50.

SADOVSKY, P. O ensino da matemática hoje: enfoques, sentidos e desafios. São Paulo: Ática, 2007.

SANTANA, J.R.M; LIMA, E.B. (2011). Pesquisa em Ensino de Ciências na atualidade: um breve estado da arte de 1990 a 2010. In V Colóquio Internacional de Educação e Contemporaneidade, 5, 2011, São Cristovão. Anais... São Cristovão.

SEVERINO, A.J. (2007). Metodologia do trabalho científico. $23^{\text {a }}$ Edição. São Paulo: Cortez, 2007.

SILVA, V.S; KLÜBER, T.E. (2012). Modelagem Matemática nos anos iniciais do ensino fundamental: uma investigação imperativa. In Revista Eletrônica de Educação. São Carlos. v. 6. n. 2, 228-249.

SILVEIRA, Everaldo. Modelagem matemática em Educação no Brasil: entendendo o universo de teses e dissertações. 2007. 197 f. Dissertação (Mestrado em Educação) Universidade Federal do Paraná, Curitiba, 2007.

STAHL, Nilson Peres. O ambiente e a modelagem matemática no ensino de cálculo numérico. 2003. 145 p. Tese (Doutorado em Educação Matemática) - Faculdade de Educação, Universidade Estadual de Campinas, Campinas, 2003.

TAMBARUSSI, Carla Melli; KLÜBER, Tiago Emanuel. Focos da pesquisa stricto sensu em Modelagem Matemática na Educação Matemática brasileira: considerações e reflexões. Educação Matemática Pesquisa. São Paulo, v. 16, n. 1, p. 209-225, 2014.

TEIXEIRA, P.M.M; NETO, J.M. (2012). O estado da arte da pesquisa em ensino de Biologia no Brasil: um panorama baseado na análise de dissertações e tese. In Revista Electrónica de Enseñanza de las Ciencias. v. 11. n. 2, 273-297. 


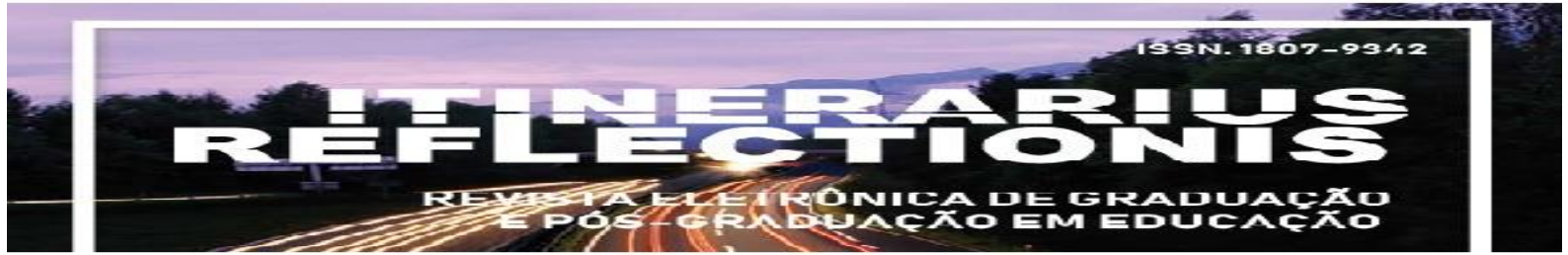

Volume, 15, número, 1, ano, 2019 